\title{
Awaria palnika retortowego stosowanego w kotłach CO Analiza przyczyn zniszczenia układu podającego - badania i technologia naprawy
}

\author{
A failure of the retort blowpipe used in central heating boilers \\ An analysis of the causes of the feeding unit damage \\ - testing and a repair technology
}

\section{Streszczenie}

W artykule przedstawiono podajnik retortowy stosowany do spalania paliw stałych w kotłach C.O. Dokonano analizy procesu spalania, który spowodował trwałe uszkodzenie elementu podającego opał. Przeprowadzono szereg badań mikroskopowych i makroskopowych złomu ślimaka w celu właściwej interpretacji zachodzących zjawisk w raz z możliwością określenia składu chemicznego, występujących struktur i własności materiałów. Scharakteryzowano ich wyniki i opracowano technikę naprawy zniszczonego elementu.

Słowa kluczowe: spawanie, uszkodzenie, naprawa

\section{Abstract}

In the article a retort feeder used to burn solid fuels in the central heating boilers is presented. An analysis of a burning process, which caused a permanent damage of an element delivering the fuel is made. Numerous micro and macroscopic examinations of the scrap of the worm were made in order to interpret all the phenomena to characterise chemical composition, structures that occur and the characteristics of the materials. Their results were interpreted and the methods of reparation of broken elements were provided.

Keywords: welding, damage, repair

\section{Wstęp}

W obecnych czasach dużym zainteresowaniem cieszą się kotły CO wraz ze sterowanym elektronicznie układem podającym paliwo z zasobnika do komory spalania. Okazuje się jednak, iż brak właściwego przeszkolenia palaczy pod względem odpowiedniej obsługi takiego urządzenia, czy nawet zwyczajny błąd ludzki może prowadzić do poważnych awarii.

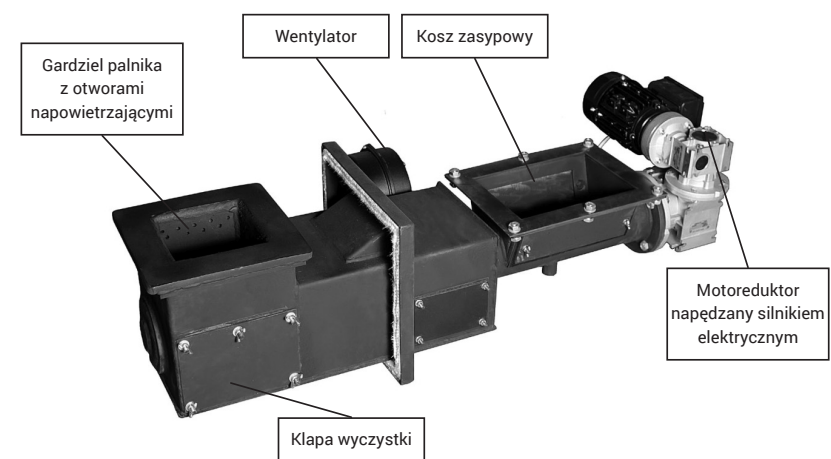

Rys. 1. Palnik retortowy wraz z podstawowymi elementami (źródło: LOGITERM)

Fig. 1. A retort blowpipe with the basic elements (source: LOGITERM)

Na rysunku 1 zaprezentowano typowy podajnik retortowy jednego z polskich producentów. Rysunek 2 z kolei prezentuje typowy ślimak stalowy, stosowany w palnikach retortowych. Zbudowany jest z pręta na który nawinięto z odpowiednim przesunięciem zwoje ślimaka.

Ważnym elementem podajnika jest sprzęgło. Jest to podzespół, który z racji ochrony przed zniszczeniem układu napędzającego pełni istotną rolę w całym układzie. Najczęściej jako mechanizmu sprzęgła bezpieczeństwa stosuje się: sprzęgło nierozłączne sztywne z kołkiem ścinanym, a rzadziej

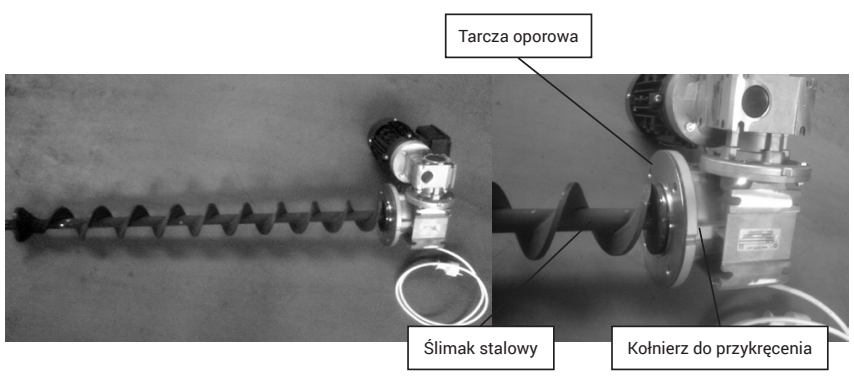

Rys. 2. Układ podający paliwo: z prawej strony wyszczególnienie najważniejszych elementów

Fig. 2. A fuel feeding unit: from the right a specification of the most important elements

Dr hab. inż. Jacek Słania, prof. PCz; dr hab. inż. Grzegorz Golański - Politechnika Częstochowska; mgr inż. Paweł Wilk - LOGITERM Koszęcin. 
przeniesienie napędu odbywa się za pomocą klina (który również ulega ścięciu). Kołek umieszczony w otworze powinien znaleźć się tam bez luzów. Z racji następującego obciążenia każdy luz może spowodować jego zerwanie podczas pracy.

Układ wysprzęglający powinien zadziałać w momencie zablokowania ślimaka. $Z$ reguły zdarzenie takie występuje gdy paliwo znajdujące się w zasobniku nie zawiera się w zakresie granulacji do jakiej przeznaczony jest dany układ podający. Czasem w węglu można znaleźć kawałki drewna lub stali, które również zakleszczając się w podajniku mogą spowodować zerwanie kołka.

\section{Przypadek ukręcenia ślimaka}

Na przedstawionych rysunkach 3 i 4 widnieje ślimak (jego elementy), który uległ zniszczeniu przez ukręcenie. Pracował w kotle o mocy $32 \mathrm{~kW}$.

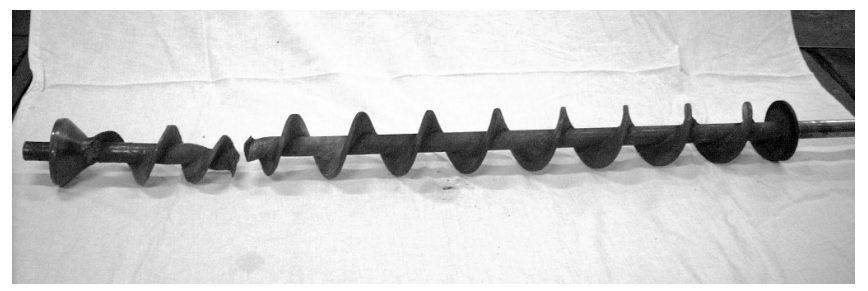

Rys. 3. Ślimak stalowy stosowany w kotłach o mocy $32 \mathrm{~kW}$ Fig. 3. A steel worm used in $32 \mathrm{~kW}$ boilers

a)

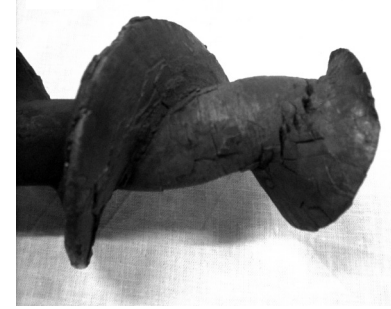

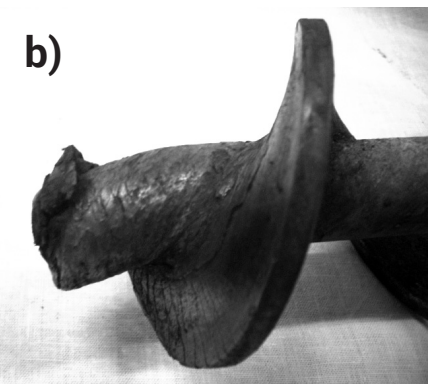

Rys. 4. a) lewa, krótka strona ślimaka, widoczne znaczne skręcenie ślimaka b) dłuższy odcinek ślimaka

Fig. 4. a) Left, short side of a worm, a visible considerable twist of a worm b) longer section of a worm

W celu analizy przyczyn powstania awarii poniżej scharakteryzowano właściwy proces spalania w omawianym palniku.

Proces palenia w palnikach retortowych powinien przebiegać w taki sposób aby miejsce głównego spalania paliwa znajdowało się powyżej krawędzi otworu palnika.

Warstwa żaru powinna mieć wysokość od kilkudziesięciu do ok. $150 \mathrm{~mm}$ w zależności od mocy palnika. Proces spalania jest wspomagany przez napływające powietrze (tlen) dzięki otworom nawiewowym znajdującym się w "gardzieli" palnika. Temperatura w palniku może wynosić od 700 do $1200^{\circ} \mathrm{C}$. Zależy ona od doboru parametrów spalania, a także od kaloryczności i rodzaju paliwa oraz miejsca pomiaru (żar; płomień). Dzięki wysokiej temperaturze następuje powolne suszenie węgla znajdującego się poniżej, w "gardzieli" palnika. Wówczas, w tym czasie istotnym etapem jest proces odgazowania paliwa, który pozytywnie oddziałuje na samo spalanie.

Źle dobrane parametry spalania (zbyt mała ilość podawanego paliwa, w zbyt małych odstępach czasu przy zbyt dużym nadmuchu powietrza) wpłynęły na miejsce znajdowania się żaru (miejsce prawidłowego palenia), które obniżyło się w dół (w głąb komory palnika), a tym samym odbywało się na wysokości zwojów ślimaka (w rurze podajnika bezpośrednio przed "gardzielą" palnika. Wysoka temperatura spowodowała uplastycznienie ślimaka, a ruch obrotowy trzpienia ślimaka (napędzanego przez motoreduktor) jego wstępne skręcenie. Tworzący się spiek w końcowej części ślimaka spowodował jego blokowanie. Najprawdopodobniej w tym momencie z racji powstania dużych oporów nastąpiło zerwanie kołka przenoszącego napęd. Jednak, ślimak nie przestał się kręcić - napęd był przekazywany w dalszym ciągu.

Oględziny poawaryjne wykazały, że w trakcie zrywania kołka łączącego tuleję motoreduktora z wałkiem ślimaka ścinany, kołek nie został zerwany w sposób prawidłowy (rys. 5a). Powstał zadzior, który poprzez obrót tulei motoreduktora utkwił w niej, dalej przenosząc napęd (rys. 5b). Ślimak pracując dalej w tak ciężkich warunkach został poddany bardzo dużym naprężeniom. Wpływ wysokiej temperatury powodował bardzo szybkie deformacje zwojów ślimaka (rys. 6), utlenianie powierzchni, a także odpadanie warstw tlenków. Taka sytuacja doprowadziła do całkowitego zniszczenia zwoju. W miejscu charakteryzującym się najmniejszym przekrojem i uszkodzeniom mechanicznym ślimak został zerwany.
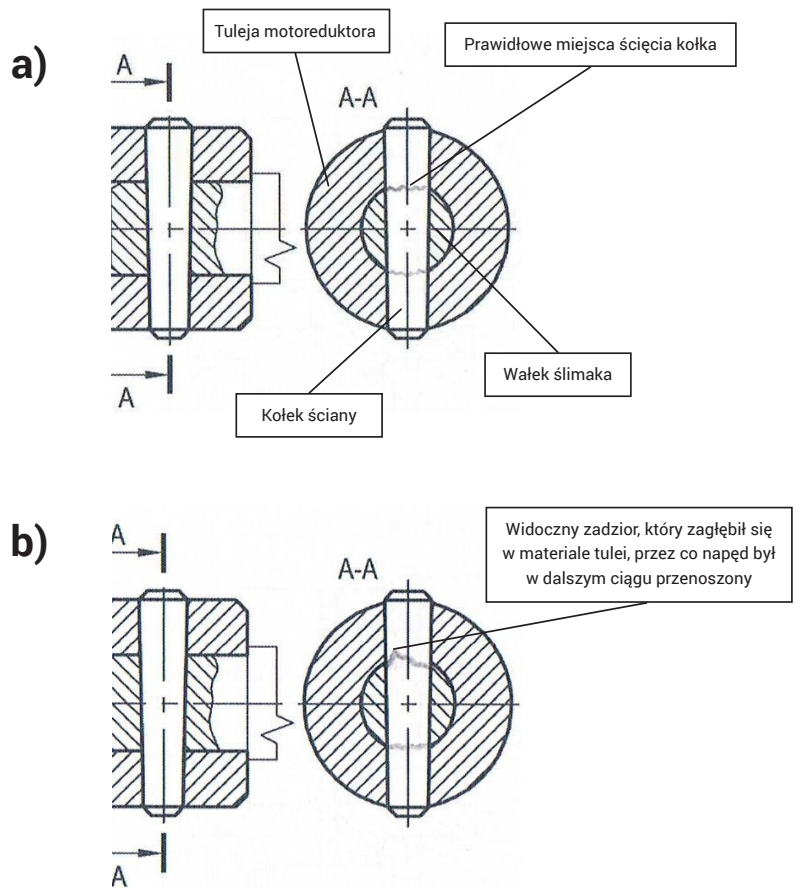

Rys. 5. Przekrój zastosowanego sprzęgła [1]

Fig. 5. An intersection of a used clutch [1]

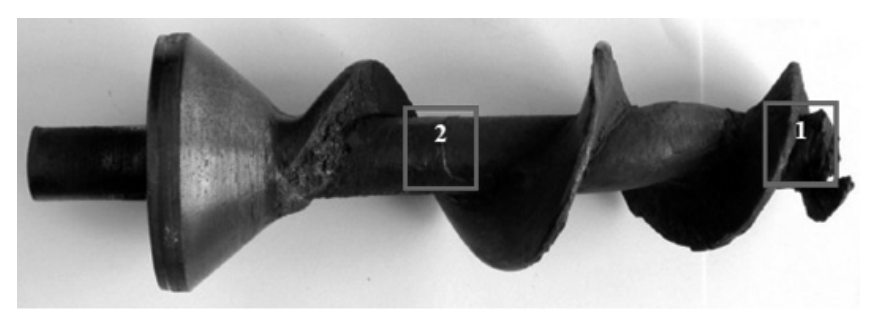

Rys. 6. Miejsce pobrania próbek do badań

Fig. 6. A sampling area

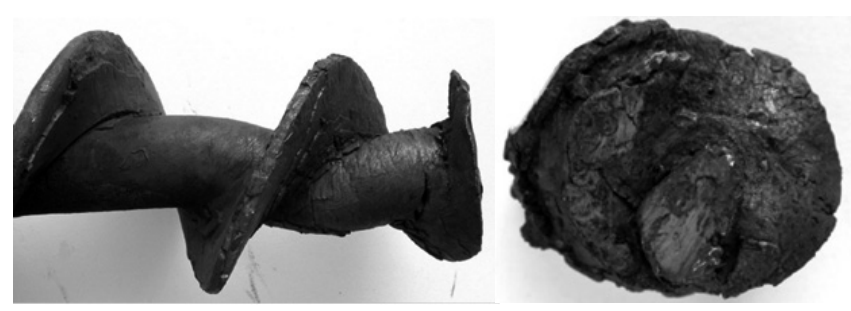

Rys. 7. Pęknięcia trzpienia, wraz z widocznymi miejscami odpadania warstw tlenków stali

Fig. 7. Cracks of the mandrel with visible areas of falling off layers of iron oxide 
Następnie przeprowadzono badania makroskopowe i mikroskopowe w celu poznania własności materiału z okolic przerwania ślimaka. Miejsca z których pobrano próbki przedstawiono na rysunku 6. Zbliżenie złomu ślimaka do badań makroskopowych ukazano na rysunku 7 . Wyniki badań mikroskopowych przedstawiono na rysunkach $8 \div 12$.

\section{Badanie mikroskopowe próbki 1}

Perlit wydzielony głównie po granicach ziaren ferrytu. Miejscami widoczna pasmowość struktury. Wielkość ziarna perlitu: 9 wg PN- EN ISO 643 [2]. Oszacowany udział objętościowy perlitu ok. $20 \%$.
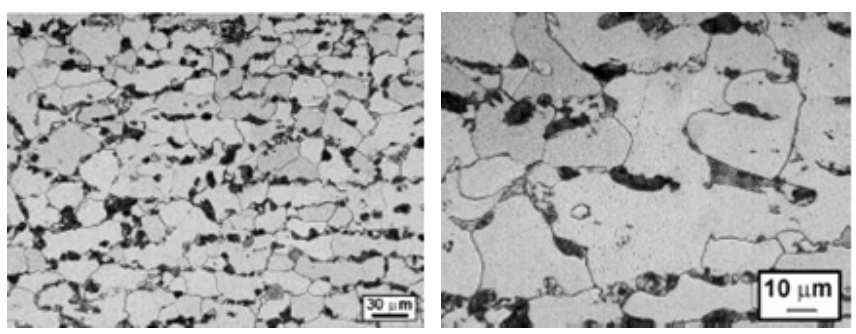

Rys. 8. Mikrostruktura ferrytyczno perlityczna

Fig. 8. Ferrite - pearlite microstructure
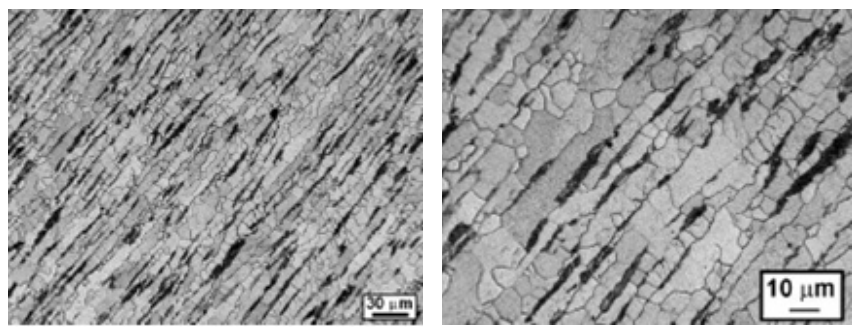

Rys. 9. Odkształcona mikrostruktura ferrytyczno - perlityczna; widoczna tekstura wskazująca na kierunek odkształcenia działającego na mikrostrukturę wałka ślimaka

Fig. 9. A deformation of a ferrite - pearlite microstructure, a visible texture showing a direction of the deformation which have an influence on a microstructure of the worm shaft
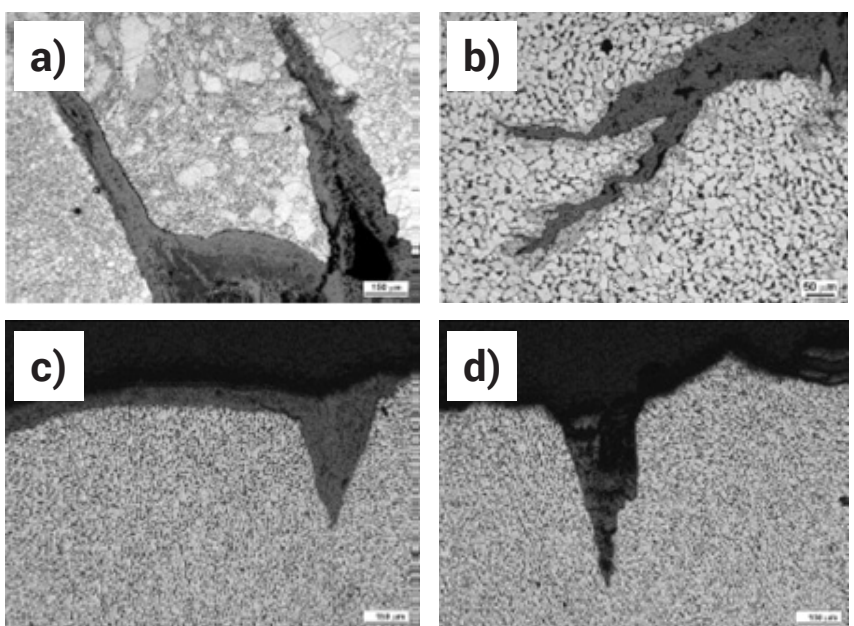

Rys. 10. Transkrystaliczne pęknięcia z rozgałęzieniami; a), b) - wypełnione produktami korozji, c) i d) bez wypełnienia

Fig. 10. Transcrystalline cracks with branches; a), b) - filled with the corrosion products, c) and d) without a filling

\section{Badanie mikroskopowe miejsca 2}

Wielkość ziarna ferrytu 5/4 (62,5 $\mu \mathrm{m} / 88,4 \mu \mathrm{m})$. Powyższa mikrostruktura wskazuje na pracę tego fragmentu wałka w temperaturze co najmniej $400 \div 500{ }^{\circ} \mathrm{C}$ - zachodzi proces rozpadu ziaren (kolonii) perlitu i proces sferoidyzacji i koagulacji węglików (cementytu).
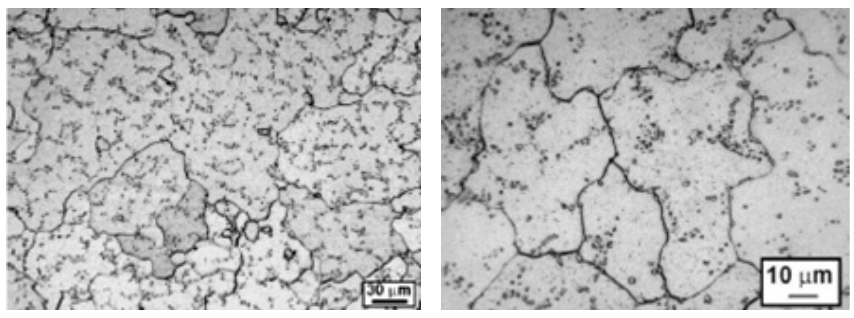

Rys. 11. Mikrostruktura ferrytyczna z licznymi wydzieleniami skoagulowanych węglików wydzielonych po granicach ziaren jak i wewnątrz

Fig. 11. A ferrite microstructure with numerous precipitations of coalesced carbides precipitated outside and inside of the grains boundaries

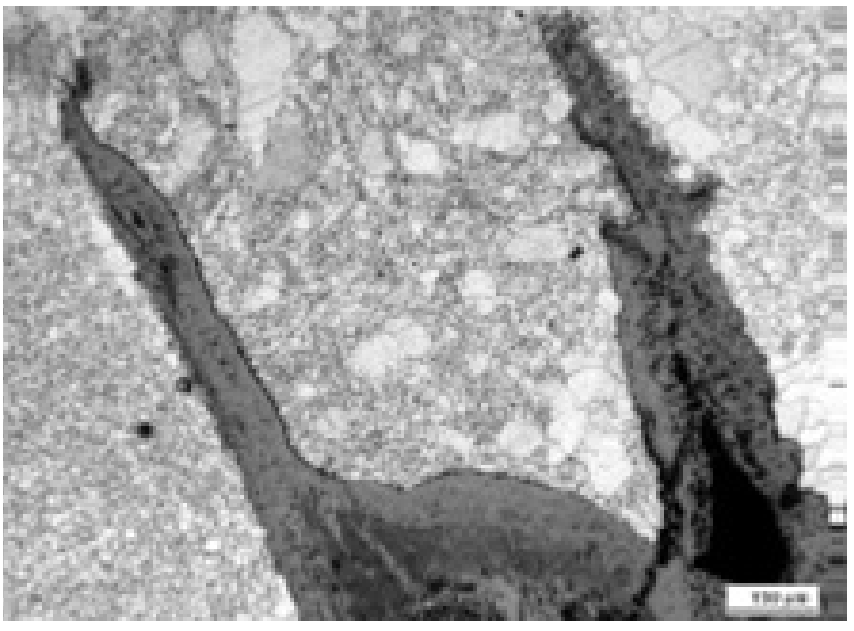

Rys. 12. Transkrystaliczne pęknięcia wypełnione produktami korozji Fig. 12. Transcrystalline cracks filled with the corrosion products

Badania wykazały, iż skład chemiczny materiału zwojów ślimaka odpowiada stali C10. Wałek wykonano natomiast z C15 wg ISO 683-18:1996. Ich skład przedstawiono w tablicy I.

Twardość wałka ślimaka (mikrostruktura ferryt + węgliki), wyznaczono poprzez średnią z pięciu prób: $95 \div 99$. Średnia 96,5 \pm 1,4 HV10.

Powyższe badania wskazują, iż główną przyczyną zniszczenia ślimaka podajnika było jego uszkodzenie w wyniku nałożenia się dwóch czynników związanych z występowaniem naprężeń zmiennych jak również obecności czynnika korozyjnego. Mechanizm takiego uszkodzenia nosi nazwę korozji zmęczeniowej. Na taki typ zniszczenia wskazuje obecność (zarówno na powierzchni w pobliżu złomu jak i poza nią) trans krystalicznych pęknięć, które prowadzą do zmniejszenia przekroju pracującego wałka, co skutkuje wzrostem naprężeń w czasie eksploatacji elementu. Okazuje się także, że złe parametry pracy podajnika (które spowodowały cofnięcie się żaru z jednoczesnym osunięciem się go na ślimak) również miały wpływ na zainicjowanie uszkodzenia.

Tablica I. Zawartość procentowa pierwiastków chemicznych wg badania stali

Table I. A percentage of chemical elements according to steel testing

\begin{tabular}{|c|c|c|c|c|c|c|c|}
\cline { 2 - 8 } \multicolumn{1}{c|}{} & $\begin{array}{c}\mathrm{C}, \\
\% \\
\text { wag. }\end{array}$ & $\begin{array}{c}\mathrm{Si}, \\
\% \\
\text { wag. }\end{array}$ & $\begin{array}{c}\mathrm{Mn}, \\
\% \\
\text { wag. }\end{array}$ & $\begin{array}{c}\mathrm{P}, \\
\% \\
\text { wag. }\end{array}$ & $\begin{array}{c}\mathrm{S}, \\
\% \\
\text { wag. }\end{array}$ & $\begin{array}{c}\mathrm{Cu}, \\
\% \\
\text { wag. }\end{array}$ & Stal \\
\hline $\begin{array}{c}\text { Zwoje } \\
\text { ślimaka }\end{array}$ & 0,11 & 0,15 & 0,52 & 0,001 & 0,012 & 0,027 & $\mathrm{C} 10$ \\
\hline Wałek & 0,16 & 0,17 & 0,62 & 0,011 & 0,012 & 0,018 & $\mathrm{C} 15$ \\
\hline
\end{tabular}




\section{Technologia naprawy ślimaka}

Zdecydowano o możliwości regeneracji zniszczonego ślimaka $z$ racji tego iż ślimak ten pracował jedynie przez okres 2 miesięcy w czasie pomiędzy sezonami (nie był bardzo obciążony pracą) i jego pozostałe zwoje były w bardzo dobrym stanie. Szerokość zwoju nowego ślimaka wynosi 6 natomiast szerokość regenerowanego 5,95 mm. Rysunek 13 przedstawia fragment części ślimaka, który nie uległ uszkodzeniu.

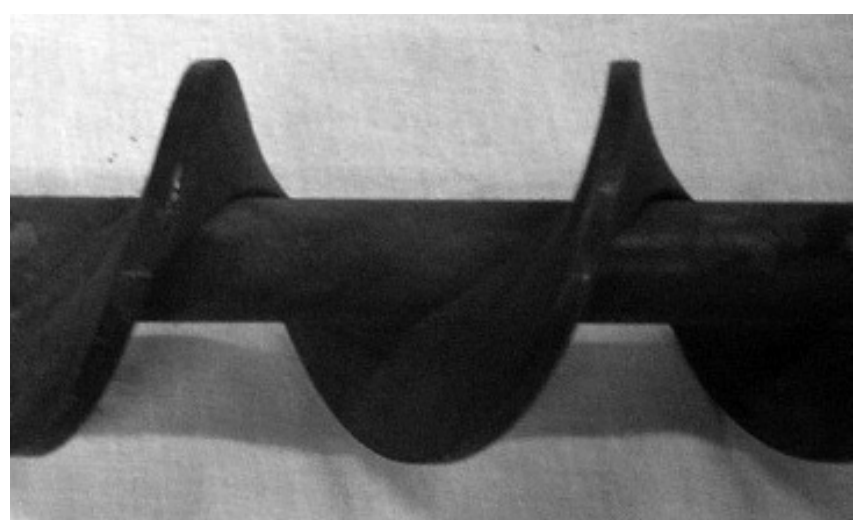

Rys. 13. Widok nieuszkodzonych powierzchni ślimaka

Fig. 13. A view of an undamaged surface of the worm

Założono, iż krótki urwany kawałek ślimaka nie nadaje się do jakiejkolwiek regeneracji. Był on poddany wysokim temperaturom, które spowodowały zmiany struktury materiału podstawowego, ale także $w$ tej części znajduje się znaczne skręcenie wałka ślimaka. Próba wyprostowania tego elementu była by po prostu bezsensem. Dlatego w jego miejsce zastosowano nowy ślimak posiadający odpowiednią długość.

Dłuższy odcinek ślimaka został skrócony o odległość delikatnego wygięcia i miejsca, do którego oddziaływała wysoka temperatura.

Naprawa polegała na połączeniu dwóch elementów ślimaka (krótkiego nowego odcinka i dłuższego oryginalnego) za pomocą procesu spawania. Zdecydowano o zastosowaniu metody MAG. Dobór materiałów dodatkowych do spawania przeprowadzono na podstawie analizy składu chemicznego materiału ślimaka (trzpień jak i uzwojenie). Zastosowano drut elektrodowy zgodnie z PN-EN ISO 14341:2011G3Si1 niestopowy drut lity miedziowany, klasy SG2.

W tablicy II ukazano składy chemiczne różnych drutów spawalniczych.

Mieszankę gazową dobrano wg PN-EN ISO 14175:2009; M 21 o składzie $\mathrm{Ar}+\left(8\right.$ do $\left.25 \% \mathrm{CO}_{2}\right)$. Przepływ mieszanki gazu osłonowego wynosił $14 \mathrm{l} / \mathrm{min}$. Elementy zostały przygotowane za pomocą frezarki uniwersalnej. Ponadto oszlifowano powierzchnie znajdujące się do $20 \mathrm{~mm}$ od krawędzi złącza.

Widok elementów przed spawaniem przedstawiają rysunki 14 i 15. Kolejność spawania została zobrazowana na rysunkach 16 i 17 .

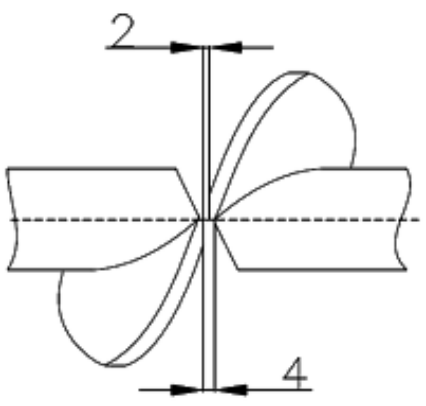

Rys. 14. Zestawienie elementów przed spawaniem Fig. 14. A specification of elements before welding

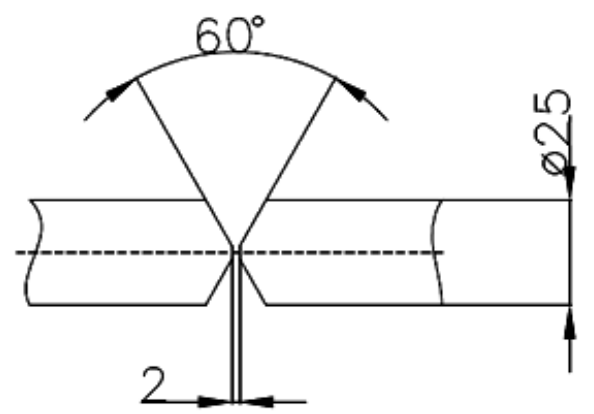

Rys. 15. Ukosowanie trzpienia ślimaka Fig. 15. Bevelling of the worm mandrel

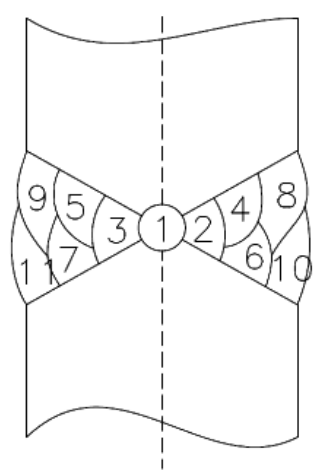

Rys. 16. Połączenie wałka - spoina czołowa na $X$ Fig. 16. A joint of the shaft - an $X$ butt weld

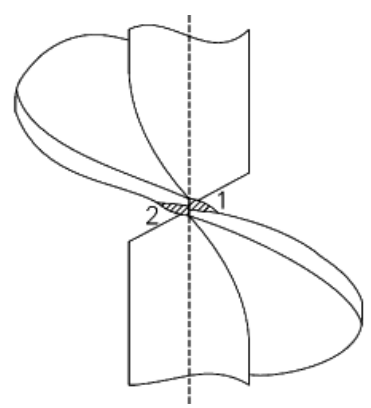

Rys. 17. Zwoje ślimaka połączono ze sobą spoiną czołową na $X$ (z powodu uformowania zwoju spoiny są niesymetryczne)

Fig. 17. The coils of the worm are joined with an $X$ butt weld (due to the formation of the coil, welds are unsymmetrical)

Tablica II. Skład chemiczny wybranych drutów spawalniczych wg PN-EN ISO 14341[3]

Table II. A chemical composition of selected welding wires according to PN-EN ISO 14341[3] standard

\begin{tabular}{|c|c|c|c|c|c|c|c|c|}
\hline Sybmole & $\mathrm{C}$ & $\mathrm{Si}$ & $\mathrm{Mn}$ & $\mathrm{P}$ i S & $\mathrm{Ni}$ & $\mathrm{Mo}$ & $\mathrm{Al}$ & $\mathrm{ZriTi}$ \\
\hline G2Si1 & $0,06 \div 0,14$ & $0,5 \div 0,8$ & $0,9 \div 1,3$ & 0,025 & 0,15 & 0,15 & 0,02 & 0,15 \\
\hline G3Si1 & $0,06 \div 0,14$ & $0,7 \div 1,0$ & $1,3 \div 1,6$ & 0,025 & 0,15 & 0,15 & 0,02 & 0,15 \\
\hline G4Si1 & $0,06 \div 0,14$ & $0,8 \div 1,2$ & $1,6 \div 1,9$ & 0,025 & 0,15 & 0,15 & 0,02 & 0,15 \\
\hline
\end{tabular}


Ilość wykorzystanego spoiwa została określona w tablicy III.

Zalecono zeszlifowanie nadlewów spoin łączących wałki ślimaków jak i ich zwoje, aby nie powodować zakłócenia podczas przesuwu paliwa w podajniku. Całość pomalowano w celu zabezpieczenia przed czynnikami korozyjnymi.
Tablica III. Objętość wykorzystanego spoiwa

Table III. An amount of a used filler metal

\begin{tabular}{|c|c|}
\hline Miejsce połączenia & Objętość $\mathrm{mm}^{2}$ \\
\hline Zwoje ślimaka & 840 \\
\hline Wałek & 2932 \\
\hline Razem & 3772 \\
\hline
\end{tabular}

\section{Podsumowanie}

Odpowiednio dobrane parametry pracy palnika ślimakowego, stosowanego do spalania paliw stałych w kotłach CO mają bardzo duże znaczenie. Niewłaściwe ustawienia, mogą prowadzić do obniżenia się żaru w głąb gardziela - na zwoje podajnika. Taka sytuacja najczęściej kończy się zdeformowaniem wałka ślimaka lub jego zniszczeniem (zerwaniem). Wiąże się to z koniecznością przeprowadzenia prac serwisowych, a także z przerwą w ogrzewaniu instalacji.

Autorzy dziękują Panu Jarosławowi Urzynicok (LOGITERM) za wnikliwą ocenę procesu spalania paliwa w palnikach retortowych.

\section{Literatura}

[1] Praca zbiorowa: Przykłady obliczeń z podstaw konstrukcji maszyn Wydawnictwa Naukowo - Techniczne, Warszawa, 2008r.

[2] PN - EN ISO 643 Stal - Mikrograficzne określanie wielkości ziarna.
[3] Ferenc K, Ferenc J.: Konstrukcje spawane, Połączenia. Wydawnictwa Naukowo - Techniczne, Warszawa 2006 r. 